\title{
Surgical Management of Coronary Artery Disease in Al-Thawrah Hospital Sana'a, Yemen 2018 To 2020
}

\author{
Nabeel Al-Mudhwahi, MD,PhD and Abeer Shaia'a Naji Sa'adan, MD ${ }^{2^{*}}$ \\ ${ }^{1}$ Cardiovascular Surgery Associate professor, Sana'a University, Yemen \\ ${ }^{2}$ Specialist Vascular Surgery, General Surgery, Sana'a University, Yemen \\ *Corresponding author: Abeer Shaia'a Naji Sa'adan, Vascular Surgery, General Surgery, Sana'a University, Yemen
}

\begin{abstract}
The incidence of ischemic heart disease (IHD) is increasing worldwide. The number of patients with IHD with or without interventions coming for non-cardiac surgical procedures are increasing. These patients have an increased risk of myocardial ischemia, myocardial infarction (MI), conduction disturbances, morbidity, and mortality during the perioperative period. This study aimed to assess the surgical management of ischemic heart disease patients in AlThawrah hospital Sana'a Yemen from 2018 to 2020. This is a cross-sectional study. 200 patients who underwent Ischemic Heart Disease surgeries. Data were collected by a self-administered questionnaire. Data was analyzed using SPSS Version 28. The findings of the study found that the success rate of the Ischemic Heart Surgery was very high $(97.5 \%)$ in comparison with only $(2.5 \%)$ failed. Interestingly, there was a significant association between Ischemic Heart Disease surgeries and using pump where the $33.3 \%$ of the surgeries were with off-pump.
\end{abstract}

\section{Keywords}

Surgical management, Coronary artery disease, Ischemic heart disease

\section{Introduction}

Cardiovascular health $(\mathrm{CVH})$ is defined by the lack of a clinical manifestation of CVD together with the presence of optimal levels of life's Simple 7 (LS7) [1]. These include 4 health behaviors: (not smoking, healthy diet pattern, sufficient physical activity, normal body weight), and 3 health factors (normal level of total cholesterol, of blood pressure, and fasting blood glucose) in the absence of drugs treatment $[2,3]$.

CVDs refer to various chronic pathology or events that have in common a pathophysiology related to atherosclerosis and including: Coronary artery disease (CAD): stable angina, unstable angina, myocardial infraction, sudden death, Cerebral vascular accident: stroke: hemorrhagic, ischemic or transit ischemic attack, Peripheral Artery Disease (PAD): Lower Extremity Artery Disease (LEAD), aortic aneurysm and Congestive heart failure (CHF). The burden of coronary artery disease, cerebral vascular accident and lower extremity artery disease $[4,5]$.

What is Known as Ischemic Heart Disease (IHD) refers to conditions that involve impairment of coronary artery blood flow. This can cause silent ischemia, angina pectoris, acute coronary syndrome (ACS) or sudden cardiac death [6]. Coronary artery disease (CAD) is a common public health problem associated with high mortality and increased health cost [7]. Ischemic Heart Disease (IHD) results from a limited blood supply to the heart muscle [8]. In over $95 \%$ of cases, the cause of IHD is coronary blood flow reduction caused by coronary artery atherosclerosis. Thus, the term "coronary heart disease" is often used to describe this syndrome [9].

Ischemic heart disease in assessment of the World Health Organization is still the most common causes of death in Poland and in the world [10]. Because of chronic ischemic heart disease in Poland, $2.5 \%$ of the population suffers, i.e. about 1 million people, of whom 100,000 . Over the last two decades in Poland, mortality from ischemic heart disease has increased in people under 65 years of age [11]. Despite wide prevention, there is a problem between the current guidelines and

Citation: Al-Mudhwahi N, Sa'adan ASN (2022) Surgical Management of Coronary Artery Disease in Al-Thawrah Hospital Sana'a, Yemen 2018 To 2020. Int Arch Vasc Med 5:013. doi.org/10.23937/26903164/1710013

Accepted: February 08, 2022: Published: February 10, 2022

Copyright: (c) 2022 Al-Mudhwahi N, et al. This is an open-access article distributed under the terms of the Creative Commons Attribution License, which permits unrestricted use, distribution, and reproduction in any medium, provided the original author and source are credited. 
Table 1: Demographic characteristics of patient.

\begin{tabular}{|c|c|c|c|}
\hline & Category & $\mathbf{N}(\%)$ & Mean ( \pm SD) \\
\hline \multirow[t]{2}{*}{ Gender } & Female & $45(22.5 \%)$ & \\
\hline & Male & $155(77.5 \%)$ & \\
\hline \multirow[t]{4}{*}{ Habits } & Smoker only & $14(7.0 \%)$ & \\
\hline & KHAT & $112(56.0 \%)$ & \\
\hline & Smoker and KHAT & $67(33.5 \%)$ & \\
\hline & None & $7(3.5 \%)$ & \\
\hline \multirow[t]{4}{*}{ Age group } & $36-45$ years & $38(19.0 \%)$ & $54.30( \pm 9.16)$ \\
\hline & $46-55$ years & $74(37.0 \%)$ & \\
\hline & $56-65$ years & $70(35.0 \%)$ & \\
\hline & $66-75$ years & $18(9.0 \%)$ & \\
\hline
\end{tabular}

the patient's continuing of recommendations. Good communication between medical staff and patient with ischemic heart disease and increasing the pressure on education is a guarantee of therapeutic success. This will be reflected in the health, social and economic sphere [12].

Cardiovascular disease is one of the most serious problems of modern times. Ischemic heart disease is still the most common cause of death in Poland and in the world. Number of deaths because of this disease will increase from 7000 in 2002 to 11000000 in 2020 [13]. This study is an attempt to assess the success rate of surgical management of coronary heart disease among patients attending Al-Thawrah Hospital Sana'a Yemen from 2018 to 2020.

\section{Methods}

This study is a cross-sectional study conducted in Al-Thawrah Hospital Sana'a Yemen. It aimed at studying the surgical management of Ischemic Heart Disease (IHD) and the success rate of such surgeries during the period from 2018 to 2020. After reviewing the medical records, nearly 600 patients underwent IHD surgical management. The inclusion criteria were cases who underwent IHD surgical management and had complete information in their medical records and that was only 200 patients and thus were recruited as the study sample. The exclusion criteria were cases with incomplete data. The data was collected by selfadministered questionnaire in addition to medical records of the patients in the hospital. Ethical approval was obtained and consents were obtained from patients before taking any action in the research.

The data were cleaned, coded, and analyzed using SPSS version 28. Frequencies and percentages were employed to describe the variables of the study. In addition, Chi square, Fisher exact test was used to examine any association between the demographic data, clinical data, and the outcome of the study. P-value less than 0.05 was considered statistically significant [14].

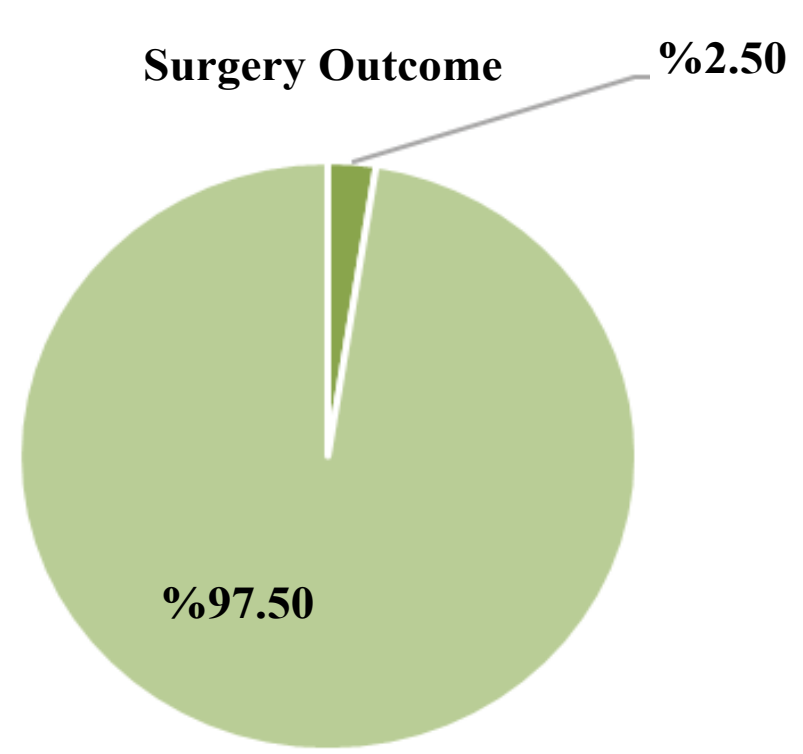

- Died $\|$ Improved

Figure 1: Surgery outcome.

\section{Ethical Declaration}

All the ethical consent forms were approved from the Ethical Committee in AL-Thawrah Hospital.

\section{Results}

Out of 200 patients, over three-fourths (77.5\%) of the patients are male while only less than one fourth (22.5\%) are female. More than half of them (56\%) chew Khat only, about one third (33.5\%) chew Kha and Smoke, $7 \%$ of them only smoke, and $3.5 \%$ of them never have any of these habits. $19 \%$ of them are aged between $36-45$ years, $37 \%$ between $46-55$ years, $35 \%$ of them between 56-65 years, and $9 \%$ of them between $66-75$ years. The age average was ( 54.30 years) with standard deviation of $( \pm 9.16)$ as shown in Table 1 .

\section{Patient status after surgery (OUTCOME)}

Figure 1 presents the summary statistics of the patient status. It is apparent that only $2.5 \%$ of the cases 
Table 2: Clinical history of the patients.

\begin{tabular}{|l|l|l|}
\hline \multirow{3}{*}{ Medical illness } & & N (\%) \\
\hline \multirow{3}{*}{ Pump use } & Ischemic Heart Disease & $185(92.5 \%)$ \\
\hline & IHD + RHD & $15(7.5 \%)$ \\
\hline Type of graft & Pump on & $197(98.5 \%)$ \\
\hline \multirow{5}{*}{ Number of grafts in CABG } & Pump off & $3(1.5 \%)$ \\
\hline & Great saphenous vein & $18(9.0 \%)$ \\
\hline & Internal Mammary artery & $5(2.5 \%)$ \\
\hline & SV+IMA & $177(88.5 \%)$ \\
\hline & CABG + 1 Graft & $16(8.0 \%)$ \\
\hline & CABG + 2 Grafts & $7(3.5 \%)$ \\
\hline & CABG + 3 Grafts & $151(75.5 \%)$ \\
\hline & CABG + 1 Graft +AVR & $5(2.5 \%)$ \\
\hline & CABG + 1 Graft + MVR & $14(7.0 \%)$ \\
\hline & CABG + 4 Grafts & $1(0.5 \%)$ \\
\hline & CABG + 2 Grafts + MVR \& TVR & $2(1.0 \%)$ \\
\hline & CABG + 1 Graft + TVR & $4(2.0 \%)$ \\
\hline
\end{tabular}

Table 3: Association between outcome and demographics.

\begin{tabular}{|c|c|c|c|c|}
\hline & & Died N (\%) & Improved N (\%) & $P$ \\
\hline \multirow[t]{2}{*}{ Gender } & Female & $1(2.2 \%)$ & $44(97.8 \%)$ & $>0.05$ \\
\hline & Male & $4(2.6 \%)$ & $151(97.4 \%)$ & \\
\hline \multirow[t]{4}{*}{ Special Habits } & Smoker only & $0(0.0 \%)$ & $14(100.0 \%)$ & $>0.05$ \\
\hline & Khat & $2(1.8 \%)$ & $110(98.2 \%)$ & \\
\hline & Smoker and Khat & $3(4.5 \%)$ & $64(95.5 \%)$ & \\
\hline & None & $0(0.0 \%)$ & $7(100.0 \%)$ & \\
\hline \multirow[t]{4}{*}{ Age } & $36-45$ years & $0(0.0 \%)$ & $38(100.0 \%)$ & $>0.05$ \\
\hline & $46-55$ years & $4(5.4 \%)$ & $70(94.6 \%)$ & \\
\hline & $56-65$ years & $1(1.4 \%)$ & $69(98.6 \%)$ & \\
\hline & $66-75$ years & $0(0.0 \%)$ & $18(100.0 \%)$ & \\
\hline
\end{tabular}

died and $97.5 \%$ of them improved. Out of 40 successful surgeries, only one surgery fails.

As shown in Table 2, most of the study sample $(92.5 \%)$ were diagnosed as having IHD. However, only 7.5\% were diagnosed as having IHD and RHD. $98.5 \%$ of the surgeries were done with on-pump on while only $1.5 \%$ of them with off-pump. $88.5 \%$ of the grafts used are SV+IMA, $9 \%$ of them are Great Saphenous vein, and $2.5 \%$ of them are Internal mammary artery. Almost three fourths $(75.5 \%)$ have CABG +3 grafts, $8 \%$ of them have CABG + 1 Graft, 7\% CABG + 1 grafts MVR, 3.5\% CABG + 2 Grafts, $2.5 \%$ CABG + 1 Graft + AVR, 2\% CABG + $1 \mathrm{Graft}+$ TVR, $1 \%$ CABG + 2 Grafts + MVR\&TVR and $0.5 \%$ CABG +4 Grafts.

\section{Association between sociodemographic data and status}

The association between the status of the patients and demographic data is shown in Table 3. Exact Fisher test was run to examine the association between sociodemographic characteristics and outcome of surgery. The findings show that there is no statistically significant association between the gender of patients and his status after the surgery $(p=0.05)$. No significant association between the patient status after surgery and special habits $(p>0.05)$. However, it is noticed that those the death rates were among those who either chewing Khat or chewing Khat and Smoking. No association was found between the patient status after surgery and age groups $(p>0.05)$. However, it is noticed that the death cases were the most among age groups (46-55 years) followed by age group (56-65 year).

\section{Association between case status and other variables}

Table 4 provides the association between the patient status after surgery and other clinical variables. Exact Fisher test was run to examine the association between the patient status after surgery and other clinical variables. However, it is noticed that the death rate among patient with IHD+RHD is higher (6.7\%) than those having Ischemic Heart Disease (2.2\%). A significant association was noticed between the status of patients after surgery and the use of pump during the surgery 
Table 4: Association between outcome and other clinical variables.

\begin{tabular}{|l|l|l|l|l|}
\hline \multirow{2}{*}{ Medical illness? } & & Died N (\%) & Improved N (\%) & $P$ \\
\hline \multirow{2}{*}{ Pump } & IHD & $4(2.2 \%)$ & $181(97.8 \%)$ & $>0.05$ \\
\cline { 2 - 4 } & IHD + RHD & $1(6.7 \%)$ & $14(93.3 \%)$ & $<0.05$ \\
\hline \multirow{2}{*}{ Type of graft } & Pump on & $4(2.0 \%)$ & $193(98.0 \%)$ & $>0.05$ \\
\hline & Pump off & $1(33.3 \%)$ & $2(66.6 \%)$ & $18(66.7 \%)$ \\
\hline & GSM & $0(0.0 \%)$ & $5(100.0 \%)$ & $172(97.2 \%)$ \\
\hline
\end{tabular}

$(p<0.05)$. It was found patients surgery with pump off $(33.3 \%)$ have death rate in comparison with only $2 \%$ of patient with pump on. This means one of each three surgeries with pump off fail. No association was found between the status of the patients after surgery and the type of grafts used $(p>0.05)$. Though no statistical association, all the death cases were found among this type of graft (SV + IMA).

\section{Discussion}

This study aimed to describe the surgical management of Ischemic heart Disease in Al-Thawarah Hospital Sana'a Yemen from 2018 to 2020.

The findings of the study showed that IHD was higher among male than female. This finding is in line with the study of Gheisari, et al. who found that the IHD among male is significantly higher than female [15]. The age of the patients with IHD was between $46-66$ years. The overall average of was 54.30 years (Male $=54.77$, Female $=52.67$ ) without any significant differences between male and female. This finding supports of Gheisari, et al. who confirmed that the age average is 57 years without any significant differences between male and female. This finding also supports the study of (Tate $R B$, et al.) who stated that the incidence of IHD occurs between the age of 45 to 65 [16]. More than one third of the patients were found to be smokers. Smoking is one of the risk factors of IDH surgical management failure. These findings reflect of those by Khalid (2011) who also found that smoking is a risk factor of IDH. He found that $45 \%$ of the IHD patients are smokers whose surgical management failed [17]. As a result, smoking should be stopped at least 4 weeks prior to surgery, and preferably for 6-8 weeks prior [18]. What is interesting in these results is that Chewing Khat was a risk Factor for IHD surgery failure in association with smoking.

The findings showed that most surgeries performed for IHD patients were successful where most of them improved. However, very few patients passed away. However, this study is not in line with (Scott, et al.) who concluded that only $83 \%$ of the surgical management of IHD were successful [19]. This could be explained that the time between that study and our study plays an important role in the increase rate of successful surgical management of IHD. The medical technology and developments nowadays are more accurate and effective than those ten years ago.

Most of the patients were found to have Ischemic Heart Disease. The findings showed that very few surgeries were performed off-pump. From the study findings, on-pump was the most preferred procedure. This could be explained that it is much safer than offpump. It is concluded by Dalén, et al. that patients undergoing off pump are at higher risk than those with on-pump [20]. However, other studies showed that there are no significant differences between offpump and on-pump surgeries [21]. Off-pump CABG was performed infrequently and there was a continuous decline in the number of procedures during the study period [20]. In addition, off-pump is used commonly for elderly patients [22]. The findings of the study displayed that SV+IMA was the most frequently used Graft in the surgical management of Ischemic Heart Disease. This could be explained that the SV is the most frequent used conduit and IMA is the most optimal type of graft [23]. It was also found that (CABG + 3 Grafts) was the most frequent surgeries done for ischemic heart disease patients in Al-Thawrah Hospital.

It was found that there is no statistically significant association between the gender of patients and his status after the surgery $(p>0.05)$. No significant association between the patient status after surgery and special habits $(p>0.05)$. However, it is noticed that those the death rates were among those who either chewing Khat or chewing Khat and Smoking. No association was found between the patient status after surgery and age groups $(p>0.05)$. However, it is noticed that the death cases were the most among age groups (46-55 years) followed by age group (56-65 year).

The findings also confirmed that there is no association between the patient status after surgery and other clinical variables. The results showed that there is no statistical association between the type of the disease and the patient status after surgery $(p>$ $0.05)$. However, it is noticed that the death rate among patient with IHD+RHD is higher (6.7\%) than those having Ischemic Heart Disease (2.2\%). No statically significant was found between patient status after surgery and disease after investigation ( $p>0.05$ ). It is also found that the death rate among those having 
IHD + MVD (6.7\%) is higher than those in IHD and other diseases. A significant association was noticed between the status of patients after surgery and the use of onpump or off-pump during the surgery $(p<0.05)$. One of each three patients underwent off-pump surgery died. $33.3 \%$ of patient's surgery with off-pump passed away in comparison with only $2 \%$ of patient with On-pump surgeries. This finding is explained by Dalén, et al. that off-pump surgeries put patients at higher risk and are preferred for elderly patients over 75-years-old [20]. This indicates one of each three surgeries with pump off fail. No association was found between the status of the patients after surgery and the type of grafts used ( $p$ $>0.05)$.

\section{Conclusion}

The study aimed to describe the surgical management of Ischemic Heart Disease in Al-Thawra Hospital Sana'a Yemen during the period 2018-2020. The surgical management of Ischemic Heart Disease in Al-Thawra Hospital Sana'a Yemen during the period 2018-2020 is a complete success. The rate of failing surgeries was insignificant. Smoking and Chewing Khat were found to be risk factors for having IHD and indicator of IHD surgery failure. The failure of IHD surgeries was noticed in the age groups between 46-66 years. Off-pump surgeries are not preferable as it is an indicator of IHD surgery failure. Though were found to be rarely used, GVS and IMA use in IHD surgeries showed no mortality rates at all. SV and IMA, though most frequently used, they are indicators of IHD failure.

\section{Acknowledgements}

We would like to acknowledge Al-Thawrah HospitalCardiology Dept. for their support and cooperation.

\section{Conflict of Interest}

The authors declare that there is no conflict of interest with any party and there was no fund.

\section{Authors Contribution}

All the authors shared in the operation and followed the patient postoperatively. All the authors have read and agreed to the final manuscript.

\section{References}

1. Sanchez E (2018) Life's simple 7: Vital but not easy. J Am Heart Assoc 7: e009324.

2. Cabeza de Baca T, Durazo EM, Rodriguez F (2018) Achieving optimal cardiovascular health: A Social epidemiological approach. Curr Epidemiol 5: 262-271.

3. Ozkan A, Turkmen M, Bozkus T, Kul M, Soslu R, et al. (2018) Determination of the relationship between healthy lifestyle behaviors, physical fitness, and risk factors of coronary heart diseases in university students. Educ Sci 8: 51.

4. Berger A, Leeper N, Zhao Q, Simpson A, Ting W, et al. (2019) Incidence of cardiovascular events among real-world patients with chronic coronary artery disease or peripheral artery disease receiving aspirin. J Am Coll Cardiol 73: 251.
5. Shawky A (2018) The relationship between the bilirubin and the severity of coronary artery disease (CAD) in patients with chronic stable angina. J Indian Coll Cardiol 8: 43-50.

6. Kaya K, Eroglu Z, Akgunduz E, Erdem Z, Gulmen MK (2018) Sudden cardiac death: Coronary artery spontaneous dissection. Int Clin Pathol J 6: 38-39.

7. Pinchevsky $Y$, Butkow N, Raal FJ, Chirwa T, Rothberg A (2020) Demographic and clinical factors associated with development of type 2 diabetes: A review of the literature. Int J Gen Med 13: 121-129.

8. Ke C, Gupta R, Shah BR, Stukel TA, Xavier D, et al. (2021) Association of hypertension and diabetes with ischemic heart disease and stroke mortality in India: The million death study. Glob Heart 16: 69.

9. Rosenthal DN (2018) Chronic heart failure in congenital heart disease including single ventricle circulation. Elsevier Inc.

10. Prasad A, Kumar S, Kr Singh B, Kumari N (2017) Mortality due to rheumatic heart disease in developing world: $A$ preventable problem. J Clin Exp Cardiolog 8: 8-11.

11. Wada K, Eguchi H, Prieto-Merino D (2015) Differences in stroke and ischemic heart disease mortality by occupation and industry among Japanese working-aged men. SSM Popul Heal 2: 745-749.

12. Nutbeam D (2000) Health literacy as a public health goal: A challenge for contemporary health education and communication strategies into the 21st century. Health Promot 15: 259-267.

13. Drozd M, Pujades-rodriguez M, Sun F, Franks KN, Lillie PJ, et al. (2021) Causes of death in people with cardiovascular disease: A prospective UK Biobank cohort study. Journal of the American Heart Association 10: e023188.

14. Erdemir $F$ (2013) How to write a materials and methods section of a scientific article? Turk Urol Derg 39: 10-15.

15. Gheisari F, Emami M, Raeisi Shahraki H, Samipour S, Nematollahi P (2020) The role of gender in the importance of risk factors for coronary artery disease. Cardio Res Pract 2020: 6527820 .

16. Tate RB, Manfreda J, Cuddy TE (1998) The effect of age on risk factors for ischemic heart disease: The Manitoba follow-up study, 1948-1993. Ann Epidemiol 8: 415-421.

17. Hbejan $K$ (2011) Smoking effect on ischemic heart disease in young patients. Hear Views 12: 1-6.

18. Ali S, Athar M, Ahmed SM (2019) Basics of CPB. Indian J Anaesth 49: 257-262.

19. Faulkner SL, Stoney WS, Alford WC, Thomas CS, Burrus GR, et al. (1997) Ischemic cardiomyopathy: Medical versus surgical treatment. J Thorac Cardiovasc Surg 74: 77-82.

20. Dalén M, Ivert T, Holzmann MJ, Sartipy U (2013) Long-term survival after off-pump coronary artery bypass surgery: A Swedish nationwide cohort study. Ann Thorac Surg 96: 2054-2060.

21. Hueb W, Lopes NH, Pereira AC, Hueb AC, Soares PR, et al. (2010) Five-year follow-up of a randomized comparison between off-pump and on-pump stable multivessel coronary artery bypass grafting. The MASS III Trial. Circulation 122: S48-S53.

22. Parissis $H$, Mbarushimana $S$, Ramesh $B C$, Parissis $M$, Lampridis S, et al. (2015) The impact of off-pump surgery in end-organ function: Practical end-points. J Cardiothorac Surg 10: 159.

23. Murashita T (2017) The choice of graft conduits in coronary artery bypass grafting. Coronary Artery Bypass Graft Surgery. 